\title{
Bending Properties of Additively Manufactured Commercially Pure Titanium (CPTi) Limited Contact Dynamic Compression Plate (LC-DCP) Constructs: Effect of Surface Treatment
}

\author{
Seungjong Lee \\ Auburn University \\ Nabeel Ahmad \\ Auburn University \\ Kayla Corriveau \\ Auburn University \\ Cameron Himel \\ Auburn University \\ Daniel Silva \\ Auburn University \\ Nima Shamsaei ( $\square$ shamsaei@auburn.edu) \\ Auburn University https://orcid.org/0000-0003-0325-7314
}

\section{Research Article}

Keywords: Additive manufacturing, Commercially pure titanium, limited contact dynamic compression plate, Surface roughness, Mechanical testing, Fatigue

Posted Date: May 29th, 2021

DOl: https://doi.org/10.21203/rs.3.rs-529184/v1

License: (c) (i) This work is licensed under a Creative Commons Attribution 4.0 International License. Read Full License

Version of Record: A version of this preprint was published at Journal of the Mechanical Behavior of Biomedical Materials on December 1st, 2021. See the published version at https://doi.org/10.1016/j.jmbbm.2021.105042. 


\section{Abstract}

\section{Background}

Additive manufacturing of metallic materials, a layer-wise manufacturing method, is currently gaining attention in the biomedical industry because of its capability to fabricate complex geometries including customized parts fitting to patient requirements. However, one of the major challenges hindering the full implementation of additively manufactured parts in safety-critical applications is their poor mechanical performance under cyclic loading. This study investigated both quasi-static bending properties (bending stiffness, bending structural stiffness, and bending strength) and bending fatigue properties of additively manufactured (AM) commercially pure titanium (CPTi) limited contact dynamic compression plate (LCDCP) constructs. The results were compared with commercially manufactured (CM) counterparts.

Methods

AM CPTi LC-DCP with different surface conditions including as-built, single shot-peened, dual shotpeened, and chemically assisted surface enhancement conditions and CM counterparts were mechanically tested based on ASTM International standard for metallic bone plates (ASTM F382). Bending stiffness, bending structural stiffness, and bending strength was measured by quasi-static bending tests, and bending fatigue properties were obtained by cyclic bending tests.

Results

Bending stiffness and bending structural stiffness of AM CPTi LC-DCPs are comparable to CM counterparts; however, the bending strength of AM CPTi LC-DCPs is lower than CM counterparts. The fatigue strength of as-built AM CPTi LC-DCPs is lower compared to the CM counterparts. However, after post surface treatments, single shot-peened, dual shot-peened, and chemically assisted surface enhancement AM CPTi LC-DCPs exhibit statistically comparable fatigue strength to the CM CPTi LCDCPs.

Conclusion

AM CPTi LC-DCP could be considered as an alternative to CM LC-DCP in applications that require less bending strength $(\sim 5.44 \mathrm{~N} \cdot \mathrm{m})$. Post surface treatment should be considered on as-built implants to improve fatigue strength.

\section{Introduction}

Metal additive manufacturing (AM) is popular because of its unique benefits such as the fabrication of complex geometries and personalized parts $[1,2]$. The production of complex geometries using traditional manufacturing techniques requires expensive tooling and customized molds, which are not economically viable for small to medium batches of production [3, 4]. As such, biomedical industries that require small-batch productions, are trying to capitalize on the "unique benefits" offered by AM 
technologies [5]. In particular, the orthopedic implant community has an increasing interest in AM technologies to imitate individual bone shapes and produce tailored and net-shaped implants for each patient [6].

Although a few studies have reported the potential of customized AM implants [7-9], there is a need to perform biomechanical comparisons to commercially available constructs to ensure adequate biomechanical properties before extensive use. This is specifically important considering AM titanium (Ti) alloys often exhibit lower mechanical performance as compared to the CM counterparts due to the presence of surface roughness or volumetric defects $[10,11]$. As an example of real application, the Limited Contact Dynamic Compression Plates (LC-DCPs) which are widely used in veterinary orthopedic surgeries can be studied due to their effective internal fixation and reduced damage to the plated bone [12]. The biomedical properties of CM CPTi and SS LC-DCP constructs have been previously reported in several publications $[13,14]$. To adopt AM technologies for fabricating implants, Xie et al. [15] showed the comparison of mechanical characteristics between customized computer numerical control (CNC) and AM Ti-6Al-4V reconstruction plates. The results indicated that not only the mechanical performances of AM plates are superior, but also the fatigue strength is sufficient compared to CNC plates. However, the mechanical properties of AM LC-DCP including overall bending fatigue behavior have not been studied and comparisons between CM LC-DCPs that currently are being used for veterinary surgeries and AM LCDCPs are demanded to utilize AM LC-DCPs in real applications.

The current stage of AM techniques requires post surface treatments as a prerequisite to enhance the fatigue strength of AM parts since the surface roughness can cause early crack initiations [16-18]. It should be mentioned that Xie et al. [15] showed sufficient fatigue strength of AM parts compared to CNC counterparts since both parts underwent the same polishing process. The subtractive machining/polishing process results in superior fatigue strengths compared to other surface treatment techniques [19,20]; however, certain geometries such as lattices and porous structures are not feasible to be machined. Therefore, the AM community have studied/developed various post surface treatments such as laser-polishing and shot-peening [21,22]. While the shot-peening may not smoothen the surface to the extent of machining and laser-polishing, it can treat the curved shapes without damaging the original geometry [23]. Therefore, shot-peening has the potential to be used as a post surface treatment of AM LC-DCP.

In this study, the biomechanical properties of AM commercially pure titanium (CPTi) LC-DCP in bending are investigated. The effect of post surface treatments including a single shot-peening (SP), dual shotpeening (DP), and chemically assisted surface enhancement (CASE) on bending fatigue strength of AM CPTi LC-DCP is also examined. We hypothesized that the results will demonstrate comparable bending strength between the AM CPTi LC-DCP to the CM counterparts and that post surface treatments will produce comparable fatigue bending strengths to the $\mathrm{CM}$ counterparts.

\section{Materials And Methods}




\subsection{Fabrication}

The CM CPTi LC-DCP is considered as a counterpart of AM CPTi LC-DCP in this study. The CM CPTi LCDCP was first 3D scanned, converted to standard triangle language (STL) format, and then imported to the LB-PBF machine EOS M290. The AM CPTi LC-DCP constructs were produced using following default process parameters of EOS M290 for Ti-6Al-4V: laser power of $280 \mathrm{~W}$, laser scan speed of $1200 \mathrm{~mm} / \mathrm{s}$, hatching distance of $0.14 \mathrm{~mm}$, and layer thickness of $30 \mu \mathrm{m}$. The build orientation of $\sim 20^{\circ}$ and default supports were employed to avoid placing any additional structures on the holes of LC-DCP. After fabrication, the entire build plate which includes both LC-DCPs and the substrate was stress relieved at $700^{\circ} \mathrm{C}$ for an hour, followed by furnace cooling to room temperature to eliminate residual stresses. Stress relieved LC-DCPs were detached from the substrate and the support structures were removed.

\subsection{Surface treatments and measurements}

Post surface treatments including a single shot-peeing (SP), dual shot-peening (DP), and chemically assisted surface enhancement (CASE) were conducted by Curtiss-Wright Surface Technology. The CASE is a two-stage process consisting of shot-peening followed by the vibratory superfinishing process. Figure 1 shows the five different groups of LC-DCPs in terms of surface conditions. The surfaces of five different conditions including as-built (AB), SP, DP, CASE, and CM were investigated by a 3D digital microscope (VHX-6000X). Based on the obtained surface profile data, surface topography was constructed using built-in software of 3D digital microscope.

\subsection{Mechanical testing}

Mechanical testing including quasi-static and cyclic four-point bending tests were conducted using a servo-hydraulic load frame (Bionix servohydraulic test system) with $25 \mathrm{kN}$ capacity. Both quasi-static and cyclic four-point bending tests were designed based on the ASTM F382 standard on specification and test method for metallic bone plates [24]. To meet the ASTM testing requirements, a four-point bend fixture (Model 642.01A-02) was used. Figure 2 shows the configurations for both quasi-static and cyclic four-point bending tests. The quasi-static bending tests were conducted first to obtain quasi-static bending properties and the cyclic bending tests were conducted based on the obtained quasi-static bending properties. During the quasi-static bending tests, the tests were stopped when the displacement reached $-10 \mathrm{~mm}$; although the plates were not broken, full load-displacement curves were already obtained. For cyclic bending tests, the tests were suspended and considered as run-outs if the number of cycles reached 1 million.

\subsection{Statistical methods}

Both data from quasi-static and fatigue tests were statistically analyzed using $\mathrm{R}$ version 4.0.3. The unbalanced Type II analysis of variance (ANOVA) and Tukey's pairwise comparisons test were conducted for fatigue results to test whether the type of manufacturing process applied to obtain each part (i.e. CM and $A M)$ and its respective post surface treatments affect its fatigue life. In order to verify assumptions 
for the ANOVA, Levene's and Shapiro-Wilk tests were also applied. The statistical significance was set at $95 \%$.

\subsection{Fractography}

The fracture surfaces of failed parts tested under cyclic loading (i.e. fatigue failure) were investigated using a 3D digital microscope and a scanning electron microscope (SEM). The entire fatigue fracture surface was observed by the 3D digital microscope first to locate the crack initiation, crack growth, and final fracture regions. The crack initiation sites, especially, were further investigated using the SEM (ZEISS Crossbeam 550) with higher magnifications.

\section{Experimental Results}

\subsection{Surface roughness}

The surface topography of each condition is distinct. Figure 3 shows the surface conditions with color maps which indicate peaks as red and valleys as blue. There were negligible topographical differences between SP, DP, and CASE conditions, hence only DP condition is presented in Fig. 3. The surface condition after the shot-peening process (Fig. 3(b)) shows reduced surface roughness compared to the $A B$ condition (Fig. 3(a)). The partially melted powder particles were eliminated or pressed down by the shot-peening process, therefore, the surface of DP is flatter than the $A B$ condition. Even though the DP condition shows a relatively smooth surface compared to the $A B$ condition, it is still rougher than the $C M$ condition (Fig. 3(c)).

\subsection{Quasi-static bending properties}

Quasi-static bending properties of AM CPTi LC-DCPs are distinct compared to CM CPTi LC-DCPs even though post surface treatments were conducted on AM parts. The load-displacement curves of AB, DP, SP, and CM CPTi LC-DCP measured during quasi-static four-point bending tests are illustrated in Fig. 4. Based on load-displacement curves, the bending stiffness $(K)$, the bending structural stiffness $\left(\mathrm{EI}_{\mathrm{e}}\right)$, the proof load $(P)$, and the bending strength are calculated and listed in Table 1. Two tests were conducted for each plate condition and no outliers were observed. The quasi-static bending properties presented in Table 1, are the average of two tests. The AM results indicate that the change due to post surface treatments is negligible. 
Table 1

Quasi-static bending properties of AB, DP, SP, and CM CPTi LC-DCPS

\begin{tabular}{|lllll|}
\hline $\begin{array}{l}\text { Specimen } \\
\text { Condition }\end{array}$ & $\begin{array}{l}\text { Proof } \\
\text { Load, } \mathbf{P}(\mathbf{N})\end{array}$ & $\begin{array}{l}\text { Bending Stiffness, } \\
\mathbf{K}(\mathbf{N} / \mathbf{m m})\end{array}$ & $\begin{array}{l}\text { Bending Structural } \\
\text { Stiffness, } \mathrm{El}_{\mathbf{e}}\left(\mathrm{Nm}^{2}\right)\end{array}$ & $\begin{array}{l}\text { Bending } \\
\text { Strength }(\mathbf{N m})\end{array}$ \\
\hline $\mathrm{AB}$ & 422.4 & 250.59 & 1.78 & 5.44 \\
\hline $\mathrm{DP}$ & 400.4 & 246.91 & 1.76 & 5.14 \\
$\mathrm{SP}$ & 406.7 & 255.46 & 1.82 & 5.24 \\
\hline $\mathrm{CM}$ & 603.4 & 239.63 & 1.70 & 7.77 \\
\hline
\end{tabular}

\subsection{Bending fatigue strength}

Bending fatigue test results show significant differences not only between manufacturing methods (e.g. $A M$ and $C M$ ), but also among different surface conditions (e.g. AB and DP). The details regarding test results are listed in Table 2 and the maximum applied load versus cycles to failure data is plotted in Fig. 5. Considering run-out as one million cycles, fatigue limits of AB, DP, SP, CASE, and CM CPTi LC-DCP are $105,210,210,315$, and $315 \mathrm{~N}$, respectively. If at least one plate was broken before reaching run-out, the corresponding load was not considered as the fatigue limit. CASE CPTi LC-DCPs show a fatigue limit at $\mathrm{F}_{\max }=315 \mathrm{~N}$ and it is comparable to $\mathrm{CM}$ counterparts. 
Table 2

Four-point bending fatigue test results including applied load amplitudes $\left(F_{a}\right)$, minimum applied loads $\left(F_{\min }\right)$, maximum applied loads $\left(F_{\max }\right)$, and cycles to failure $\left(\mathrm{N}_{\mathrm{f}}\right)$ for plates with five different manufacturing/surface conditions including AB, DP, SP, CASE, and CM

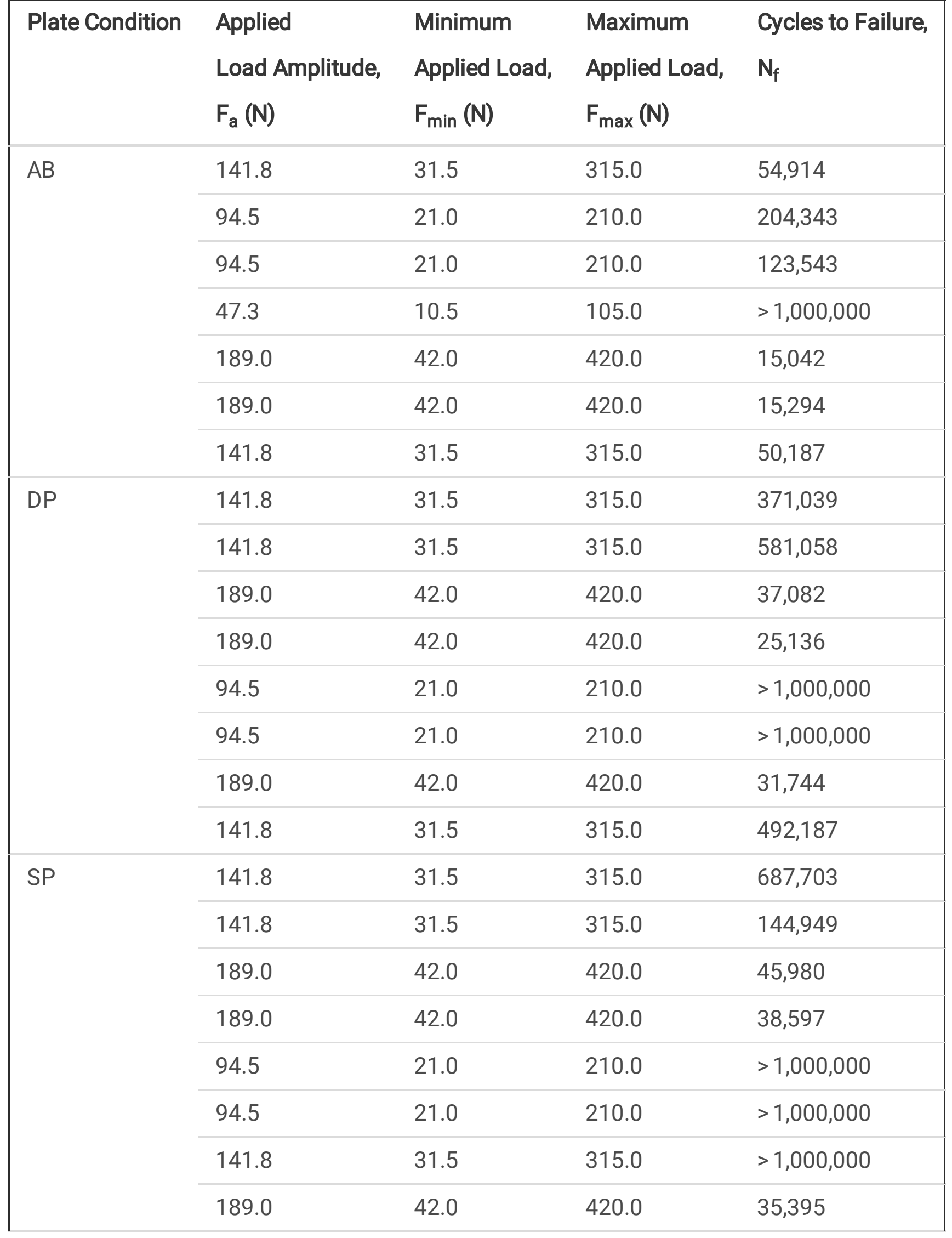




\begin{tabular}{|c|c|c|c|c|}
\hline \multirow[t]{3}{*}{ Plate Condition } & Applied & Minimum & Maximum & Cycles to Failure, \\
\hline & Load Amplitude, & Applied Load, & Applied Load, & $N_{f}$ \\
\hline & $F_{a}(N)$ & $F_{\min }(N)$ & $\mathrm{F}_{\max }(\mathrm{N})$ & \\
\hline \multirow[t]{4}{*}{ CASE } & 189.0 & 42.0 & 420.0 & 65,666 \\
\hline & 189.0 & 42.0 & 420.0 & 66,716 \\
\hline & 141.8 & 31.5 & 315.0 & $>1,000,000$ \\
\hline & 141.8 & 31.5 & 315.0 & $>1,000,000$ \\
\hline \multirow[t]{6}{*}{ CM } & 94.5 & 21.0 & 210.0 & $>1,000,000$ \\
\hline & 141.8 & 31.5 & 315.0 & $>1,000,000$ \\
\hline & 189.0 & 42.0 & 420.0 & 96,256 \\
\hline & 189.0 & 42.0 & 420.0 & 70,554 \\
\hline & 141.8 & 31.5 & 315.0 & $>1,000,000$ \\
\hline & 189.0 & 42.0 & 420.0 & $>1,000,000$ \\
\hline
\end{tabular}

\subsection{Statistical analyses}

As a statistical method, Type II unbalanced analysis of variance (ANOVA) and Tukey's pairwise test for fatigue failure data were utilized using the experimental data of AB, DP, SP, and CM CPTi LC-DCPs to estimate the difference in terms of fatigue strength. The CASE plates were not included in this analysis due to the limited number of data points generated. The ANOVA results suggest that both the surface condition and the applied load impact the fatigue lives. At a significance of $95 \%$, the p-value are $9.5 \mathrm{e}-04$ for surface condition and 3.8e-05 for applied load, so we reject the null hypothesis that each of these factors does not affect fatigue life. The assumptions for the ANOVA are verified using Levene test for heteroscedasticity and Shapiro-Wilk for normality of residuals.

The results of Tukey's pairwise test using the same dataset are shown in Table 3. According to Tukey's pairwise test, the fatigue lives of the $A B$ condition are pairwise different from every other condition even after adjusting for differences in the maximum applied load. Conversely, the fatigue lives of SP, DP, and $\mathrm{CM}$ conditions are not pairwise from each other. It validates that the fatigue strength of SP, DP, and CM conditions are not statistically different. Even though the CASE condition was not statistically evaluated, it can be assumed that it will be statistically similar to the CM condition since CASE plates have longer fatigue lives than SP and DP plates. 
Table 3

The results of Tukey's pairwise test for four different manufacturing/surface conditions including $A B, D P, S P$, and $C M$

\begin{tabular}{|llllll|}
\hline Contrast & Estimate & Sum of square errors & Degree of freedom & $\begin{array}{l}\text { T-statistic } \\
\text { (F-value) }\end{array}$ & P-value \\
\hline AB-DP & -406505 & 142606 & 22 & -2.851 & 0.0428 \\
\hline AB-SP & -458303 & 142606 & 22 & -3.214 & 0.0194 \\
\hline AB-CM & -736798 & 153606 & 22 & -4.797 & 0.0005 \\
\hline DP-SP & -51797 & 131724 & 22 & -0.393 & 0.9789 \\
\hline DP-CM & -330293 & 142919 & 22 & -2.311 & 0.1260 \\
\hline SP-CM & -278496 & 142919 & 22 & -1.949 & 0.2376 \\
\hline Results are averaged over the levels of the maximum applied load. & & \\
\hline P-value adjustment: Tukey's method for comparing a family of 4 estimates. & \\
\hline
\end{tabular}

\subsection{Fractography}

The final fracture surfaces due to fatigue failure show different characteristics according to plates' manufacturing/surface conditions. Figure 6 shows fractography images of (a) AB, (b) DP, (c) SP, (d) CASE, and (e) CM CPTi LC-DCPs captured by the 3D digital microscope. Based on the overall fracture surfaces shown in Fig. 6, cracks predominantly initiated from the bottom surface (shown by red arrows in Fig. 6). During the onset of bending loads, the bottom surface undergoes the maximum tensile stresses and the likelihood of crack initiation from the bottom side of the plate becomes higher compared to the top side of the plate, which is under compressive stresses. The CM plate (Fig. 6(e)) indicated different fracture morphologies such as a clear boundary between crack growth (shown by orange arrows in Fig. 6(e)) and final fracture regions (shown by white arrows in Fig. 6(e)) and finer cleavages and dimples compared to AM (including AB, DP, SP, and CASE) plates. It should be noted that there is a certain difference in microstructures due to the different manufacturing and heat treatment processes [25].

Highly magnified SEM images in Fig. 7 provide more details regarding the differences in crack initiation in $A B, D P$, and CM CPTi LC-DCPs. Among the plates after post surface treatments, only DP is displayed in Fig. 7 since SP and CASE have similar fractographic features to DP. The AB plate had multiple cracks (red arrows in Fig. 7(a-1)), each initiated from micro-notches (red areas in Fig. 7(a-3)) formed due to the layerby-layer nature of AM process. Interestingly, DP plate had the main crack initiated from the internal facets, not from the surface (shown by orange area in Fig. 7(b-3)). This observation confirms that post surface treatment improves the surface condition and results in moving crack initiation sites from the surface to sub-surface, which ultimately enhances the fatigue performance. The CM plate shows crack initiations from the surface due to intrusions/extrusions and occasionally from the internal facet (indicated by blue arrow and area in Fig. 7(c-3)) [26]. 


\section{Discussion}

The $A B$ surface condition shows inevitable roughness due to the layer-by-layer fabrication process during AM. Partially melted powder particles are attached to the surface of the AB plate and result in relatively high peaks on the surface. The post surface treatment, shot-peening in this study, reduced surface roughness by either removing or squashing most of the remaining partially melted powder particles, as shown in the case of DP in Fig. 3(b). However, shot-peening was unable to form completely smooth surface because the process did not subtract/carve the surface, hence left behind remnant waviness as shown in Fig. 3(b). This remnant waviness of the surface causes early crack initiations in the surface treated AM plates compared to the CM counterparts, which possess a much smoother surface because of the fine surface finishing.

While the surface was smoothed by post surface treatments, quasi-static bending properties did not show significant change. The AM CPTi LC-DCPs (including AB, DP, and SP) showed similar bending stiffness and bending structural stiffness to CM CPTi LC-DCPs; however, the bending strength was found to be lower for AM plates as compared to the CM ones. This is because CM CPTi LC-DCPs are either annealed or cold-worked and have finer grains as compared to the AM CPTi LC-DCPs [27]; thus, CM plates exhibit higher yield strength and ultimate tensile strength [28]. The required bending strength of specific applications should be therefore considered before using AM CPTi LC-DCPs.

The effect of post surface treatments on bending fatigue strength was also explored in this study. The $A B$ plates showed the lowest fatigue limit; on the other hand, the CM plates showed the highest fatigue limit. While DP and SP conditions exhibited improved fatigue strengths compared to the AB condition, it was difficult to evaluate the disparity in the fatigue behavior of post surface treated AM plates (DP and SP) and CM plates, solely based on the experimentally obtained fatigue limits. Based on the statistical calculations, $A B$ condition had a lower fatigue strength than the CM condition, while DP and SP were all comparable to $\mathrm{CM}$ condition. It should be noted that CASE condition also had a comparable experimentally obtained fatigue limit to the one for CM counterpart (315 N which is $52.5 \%$ of CM LCDCP's proof load).

This study provides valuable early data on the use of additive manufacturing for fabrication of orthopedic implants and how it compares to a commercially available construct. This and further biomechanical testing is necessary to ensure safety and performance towards future goals of developing custom designed orthopedic implants. Custom AM plates could provide complex, individualized designs for the unique anatomy of the various bone structures and patient sizes encountered in human and veterinary medicine.

\section{Conclusions}

In this study, biomechanical properties including quasi-static bending properties and bending fatigue strengths of additively manufactured (AM) and conventionally manufactured (CM) commercially pure 
titanium (CPTi) limited contact dynamic compression plates (LC-DCPs) were examined. Post surface treatments were conducted to investigate the effect of surface roughness on bending properties. The performed experiments and analyses yielded the following conclusions:

1. The bending stiffness $(K)$ and bending structural stiffness $\left(E I_{e}\right)$ of the AM CPTi LC-DCPs are comparable to the CM counterpart. In addition, the quasi-static properties of AM plates cannot be improved by the employed post surface treatments.

2. The bending fatigue strength of AM CPTi LC-DCPs with AB surface condition is significantly less than the $\mathrm{CM}$ counterparts due to the inevitable surface roughness caused during the layer-by-layer fabrication process.

3. Bending fatigue strengths of AM CPTi LC-DCPs after post surface treatments (DP and SP conditions) are less than $\mathrm{CM}$ counterparts based on the experimentally obtained fatigue limits; however, there is not enough evidence to suggest that fatigue lives of DP, SP, and CM plates are statistically different.

4. CASE CPTi LC-DCPs show comparable experimentally obtained fatigue limit to the one for CM counterparts ( $315 \mathrm{~N}$ which is $52.5 \%$ of CM LC-DCP's proof load).

5. AM CPTi LC-DCPs after a proper post surface treatment can be considered as an alternative to $\mathrm{CM}$ LC-DCPs in applications that require less bending strength $(\sim 5.44 \mathrm{~N} \cdot \mathrm{m})$.

\section{Nomenclature}

\begin{tabular}{ll}
$\mathrm{K}$ & Bending stiffness \\
\hline $\mathrm{El}_{\mathrm{e}}$ & Bending structural stiffness \\
\hline $\mathrm{F}_{\mathrm{a}}$ & Applied load amplitude \\
\hline $\mathrm{F}_{\mathrm{min}}$ & Minimum applied load \\
\hline $\mathrm{F}_{\mathrm{max}}$ & Maximum applied load \\
\hline $\mathrm{N}_{\mathrm{f}}$ & Cycles to failure \\
\hline $\mathrm{P}$ & Proof load \\
\hline $\mathrm{R}_{\mathrm{a}}$ & Arithmetical mean height of the profiled line \\
\hline $\mathrm{R}_{\mathrm{q}}$ & Root mean square deviation of the profiled line \\
\hline $\mathrm{R}_{\mathrm{v}}$ & Maximum valley depth of the profiled line
\end{tabular}

\section{Abbreviations}




\begin{tabular}{ll} 
AB & As-built \\
\hline AM & Additive manufacturing/Additively manufactured \\
\hline ANOVA & Analysis of variance \\
\hline CASE & Chemically assisted surface enhancement \\
\hline CM & Conventionally manufactured \\
\hline CPTi & Commercially pure titanium \\
\hline DP & Dual shot-peening \\
\hline HIP & Hot isostatic pressing \\
\hline LB-PBF & Laser beam powder bed fusion \\
\hline LC-DCP & Limited contact dynamic compression plate \\
\hline SEM & Scanning electron microscope/microscopy \\
\hline SP & Single shot-peeing \\
\hline SS & Stainless steel \\
\hline STL & Standard triangle language \\
\hline Ti & Titanium \\
\hline CNC & Computer numerical control
\end{tabular}

\section{Declarations}

Ethics approval and consent to participate: Not applicable

Consent for publication: Not applicable

Availability of data and materials: Not applicable

Competing interests: The authors declare that they have no competing interests

Funding: This work was partially funded by the Auburn University's Presidential Award for Interdisciplinary Research (PAIR).

Authors' contributions: S.L. contributed to conception, design of the work, acquisition, analysis, and interpretation of data. N.A. contributed to analysis, and interpretation of data. K.C. contributed to conception, design of the work, and interpretation of data. C.H. contributed to conception. D.S. contributed to analysis, and interpretation of data. N.S. contributed to conception, design of the work, analysis, and interpretation of data. All authors have drafted the work and substantively revised the manuscript. 
Acknowledgements: The authors would like to acknowledge Curtiss-Wright metal improvements, Romulus, MI for performing the post surface treatments (single shot-peening, dual shot-peening, and chemically assisted surface enhancement) for this study.

\section{References}

1. Frazier WE. Metal additive manufacturing: A review. J. Mater. Eng. Perform. 2014. p. 1917-28.

2. Thompson SM, Bian L, Shamsaei N, Yadollahi A. An overview of Direct Laser Deposition for additive manufacturing; Part I: Transport phenomena, modeling and diagnostics. Addit Manuf [Internet]. Elsevier B.V.; 2015;8:36-62. Available from: http://dx.doi.org/10.1016/j.addma.2015.07.001

3. Horn TJ, Harrysson OLA. Overview of current additive manufacturing technologies and selected applications. Sci Prog. 2012;95:255-82.

4. Emelogu A, Marufuzzaman M, Thompson SM, Shamsaei N, Bian L. Additive manufacturing of biomedical implants: A feasibility assessment via supply-chain cost analysis. Addit Manuf [Internet]. Elsevier B.V.; 2016;11:97-113. Available from: http://dx.doi.org/10.1016/j.addma.2016.04.006

5. Singh S, Ramakrishna S. Biomedical applications of additive manufacturing: Present and future. Curr Opin Biomed Eng [Internet]. Elsevier Ltd; 2017;2:105-15. Available from: http://dx.doi.org/10.1016/j.cobme.2017.05.006

6. Javaid M, Haleem A. Additive manufacturing applications in medical cases: A literature based review. Alexandria J Med [Internet]. Alexandria University Faculty of Medicine; 2018;54:411-22. Available from: https://doi.org/10.1016/j.ajme.2017.09.003

7. Nakano T, Ishimoto T. Powder-based additive manufacturing for development of tailor-made implants for orthopedic applications. KONA Powder Part J. 2015;32:75-84.

8. Wysocki B, Maj P, Sitek R, Buhagiar J, Kurzydłowski KJ, Świeszkowski W. Laser and electron beam additive manufacturing methods of fabricating titanium bone implants. Appl Sci. 2017;7:1-20.

9. Harrysson OLA, Marcellin-Little DJ, Horn TJ. Applications of Metal Additive Manufacturing in Veterinary Orthopedic Surgery. Jom. 2015;67:647-54.

10. Pegues JW, Shao S, Shamsaei N, Sanaei N, Fatemi A, Warner DH, et al. Fatigue of additive manufactured Ti-6Al-4V, Part I: The effects of powder feedstock, manufacturing, and post-process conditions on the resulting microstructure and defects. Int J Fatigue. 2020;132:105358.

11. Molaei R, Fatemi A, Sanaei N, Pegues J, Shamsaei N, Shao S, et al. Fatigue of additive manufactured Ti-6Al-4V, Part II: The relationship between microstructure, material cyclic properties, and component performance. Int J Fatigue. 2020;132.

12. Perren SM, Mane K, Pohler O, Predieri M, Steinemann S, Gautier E. The limited contact dynamic compression plate (LC-DCP). Arch Orthop Trauma Surg. 1990;109:304-10.

13. Blake CA, Boudrieau RJ, Torrance BS, Tacvorian EK, Cabassu JB, Gaudette GR, et al. Single cycle to failure in bending of three standard and five locking plates and plate constructs. Vet Comp Orthop Traumatol. 2011;24:408-17. 
14. Cabassu JB, Kowaleski MP, Shorinko JK, Blake CA, Gaudette GR, Boudrieau RJ. Single cycle to failure in torsion of three standard and five locking plate constructs. Vet Comp Orthop Traumatol. 2011;24:418-25.

15. Xie $P$, Ouyang H, Deng $Y$, Yang $Y, X u$ J, Huang W. Comparison of conventional reconstruction plate versus direct metal laser sintering plate: An in vitro mechanical characteristics study. J Orthop Surg Res. Journal of Orthopaedic Surgery and Research; 2017;12:1-9.

16. Shamsaei N, Yadollahi A, Bian L, Thompson SM. An overview of Direct Laser Deposition for additive manufacturing; Part II: Mechanical behavior, process parameter optimization and control. Addit Manuf [Internet]. Elsevier B.V.; 2015;8:12-35. Available from: http://dx.doi.org/10.1016/j.addma.2015.07.002

17. Yadollahi A, Shamsaei N. Additive manufacturing of fatigue resistant materials: Challenges and opportunities. Int J Fatigue [Internet]. Elsevier Ltd; 2017;98:14-31. Available from: http://dx.doi.org/10.1016/j.ijfatigue.2017.01.001

18. Masuo H, Tanaka Y, Morokoshi S, Yagura H, Uchida T, Yamamoto Y, et al. Influence of defects, surface roughness and HIP on the fatigue strength of Ti-6Al-4V manufactured by additive manufacturing. Int J Fatigue [Internet]. Elsevier; 2018;117:163-79. Available from: https://doi.org/10.1016/j.ijfatigue.2018.07.020

19. Lee S, Pegues J, Shamsaei N. Fatigue Behavior and Modeling for Additive Manufactured 304L Stainless Steel: The effect of Surface Roughness. Int J Fatigue. 2020;141:105856.

20. Kahlin M, Ansell H, Basu D, Kerwin A, Newton L, Moverare JJ. Improved fatigue strength of additively manufactured Ti6Al4V by surface post processing. Int J Fatigue [Internet]. Elsevier; 2020;134:105497. Available from: https://doi.org/10.1016/j.ijfatigue.2020.105497

21. Maleki E, Bagherifard S, Bandini M, Guagliano M. Surface post-treatments for metal additive manufacturing: Progress, challenges, and opportunities. Addit Manuf [Internet]. Elsevier B.V.; 2020;37:101619. Available from: https://doi.org/10.1016/j.addma.2020.101619

22. Lee S, Ahmadi Z, Pegues JW, Mahjouri-Samani M, Shamsaei N. Laser polishing for improving fatigue performance of additive manufactured Ti-6Al-4V parts. Opt Laser Technol [Internet]. Elsevier Ltd; 2021;134:106639. Available from: https://doi.org/10.1016/j.optlastec.2020.106639

23. AlMangour B, Yang JM. Improving the surface quality and mechanical properties by shot-peening of 17-4 stainless steel fabricated by additive manufacturing. Mater Des [Internet]. Elsevier Ltd; 2016;110:914-24. Available from: http://dx.doi.org/10.1016/j.matdes.2016.08.037

24. ASTM - F382-17. Standard Specification and Test Method for Metallic Bone Plates. Annu B ASTM Stand. 2017;

25. Attar H, Ehtemam-Haghighi S, Kent D, Wu X, Dargusch MS. Comparative study of commercially pure titanium produced by laser engineered net shaping, selective laser melting and casting processes. Mater Sci Eng A [Internet]. Elsevier B.V.; 2017;705:385-93. Available from: http://dx.doi.org/10.1016/j.msea.2017.08.103 
26. Stephens RI, Fatemi A, Stephens RR, Fuchs HO. Metal fatigue in engineering. 2nd ed. John Wiley \& Sons; 2000.

27. Sergueeva A V., Stolyarov V V., Valiev RZ, Mukherjee AK. Advanced mechanical properties of pure titanium with ultrafine grained structure. Scr Mater. 2001;45:747-52.

28. Attar H, Bermingham MJ, Ehtemam-Haghighi S, Dehghan-Manshadi A, Kent D, Dargusch MS. Evaluation of the mechanical and wear properties of titanium produced by three different additive manufacturing methods for biomedical application. Mater Sci Eng A [Internet]. Elsevier B.V.; 2019;760:339-45. Available from: https://doi.org/10.1016/j.msea.2019.06.024

\section{Figures}
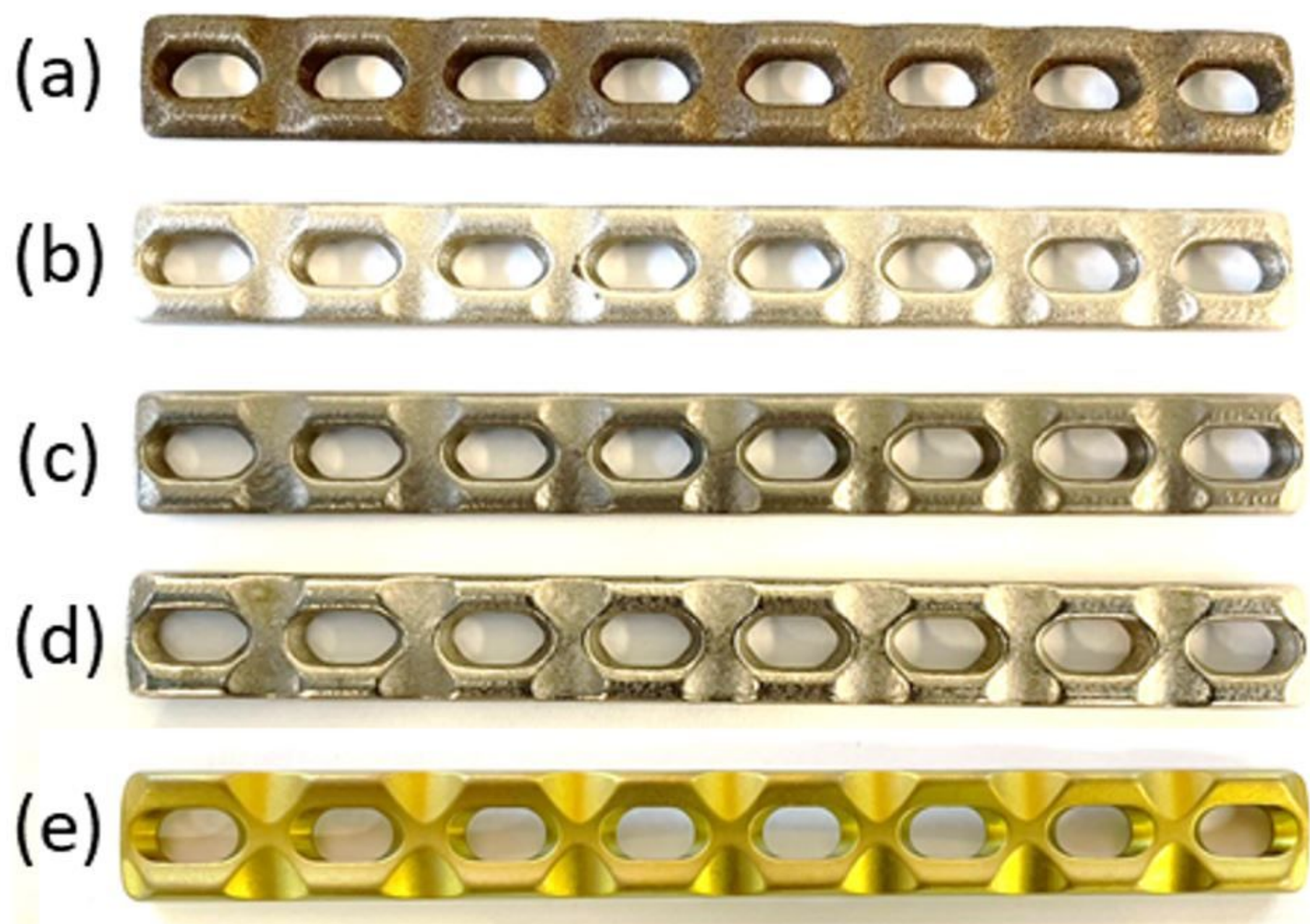

\section{Figure 1}

Images of (a) as-built, (b) single shot-peened (SP), (c) dual shot-peened (DP), (d) chemically assisted surface enhancement (CASE), and (e) conventionally manufactured (CM) LC-DCPs 


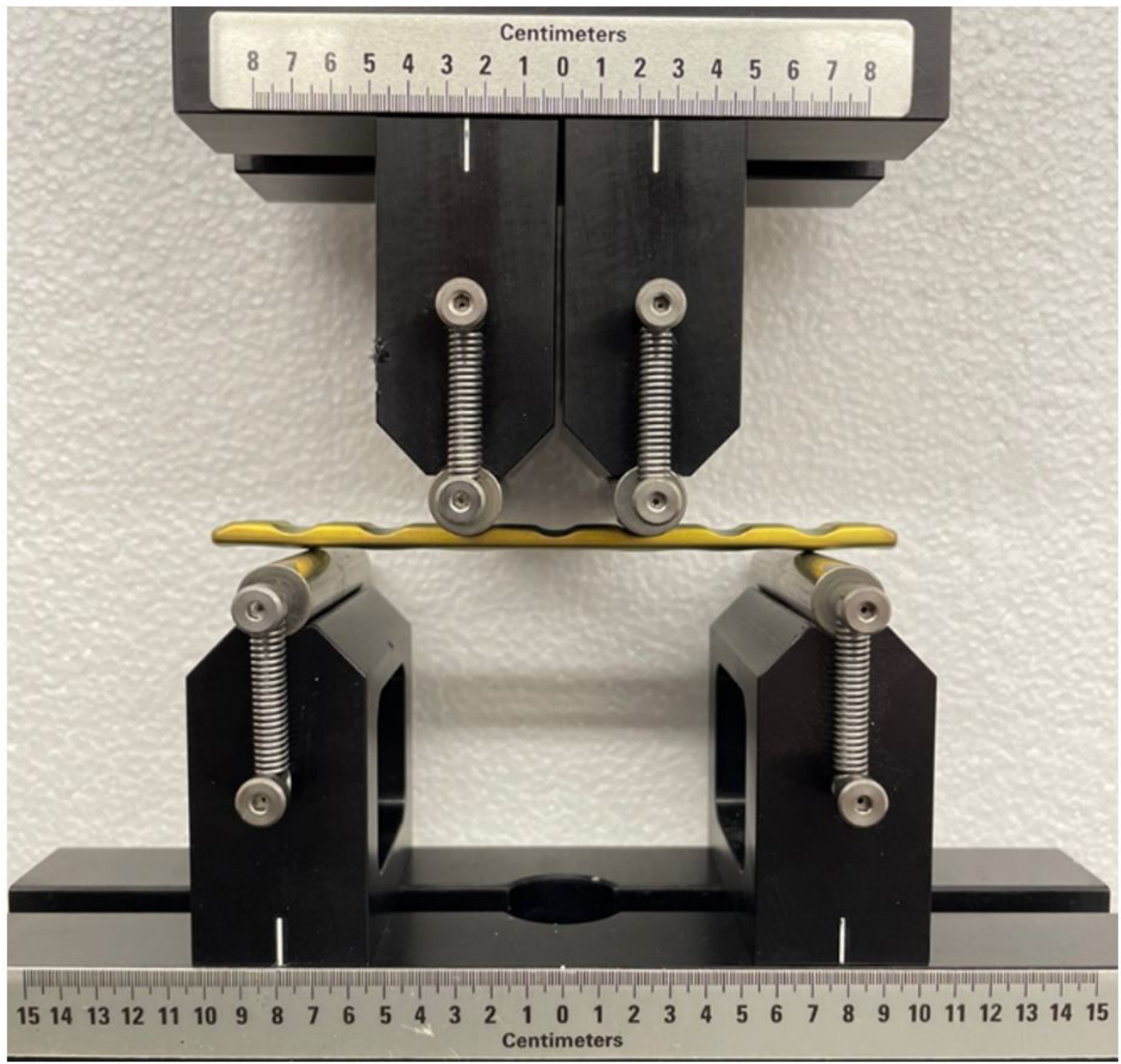

Figure 2

Test configurations including the four-point bend fixture (Model 642.01A-02) used for both quasi-static and cyclic four-point bending tests 

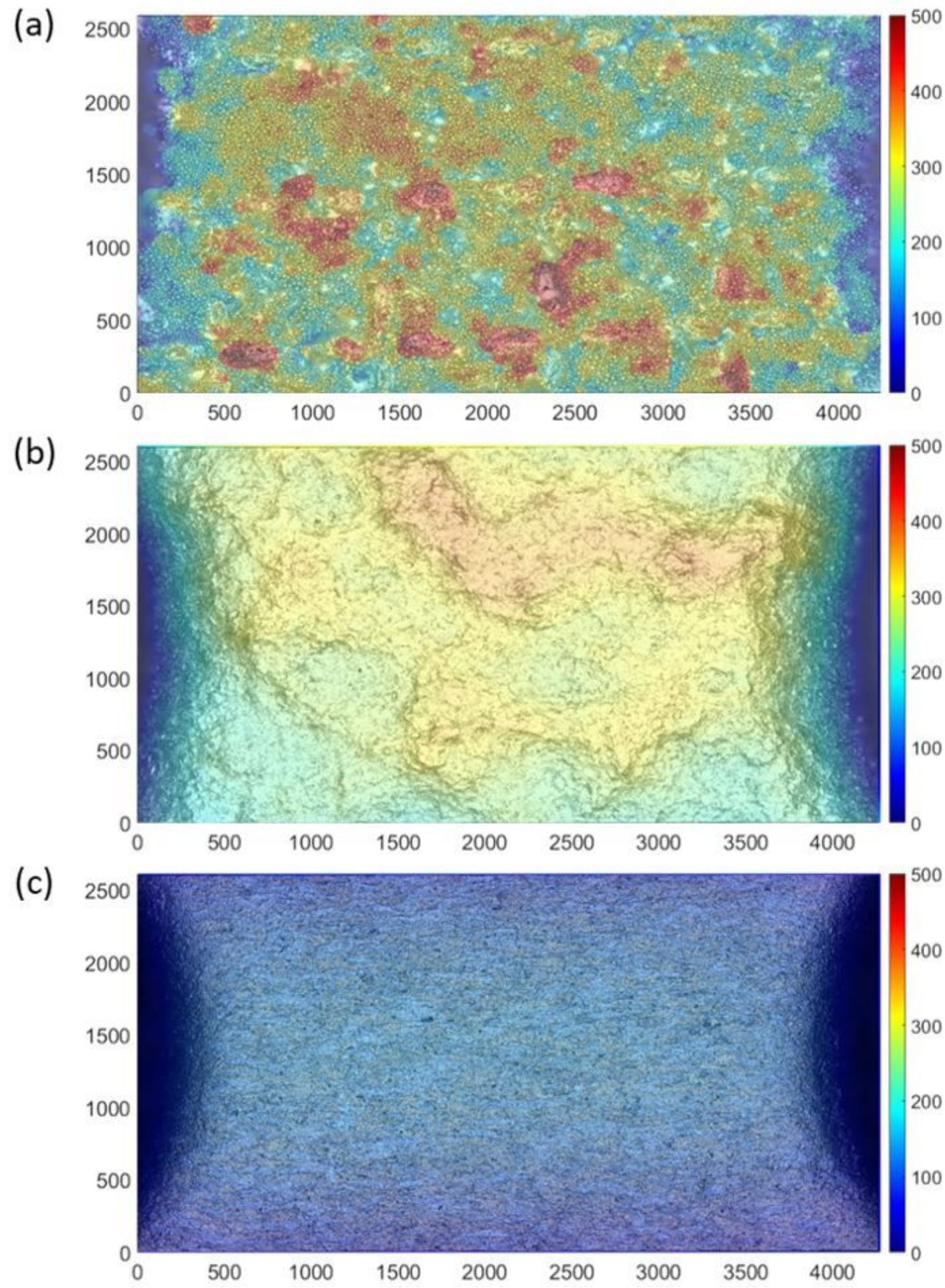

\section{Figure 3}

Surface topographical images of (a) AB, (b) DP, and (c) CM CPTi LC-DCPs captured by a 3D digital microscope 


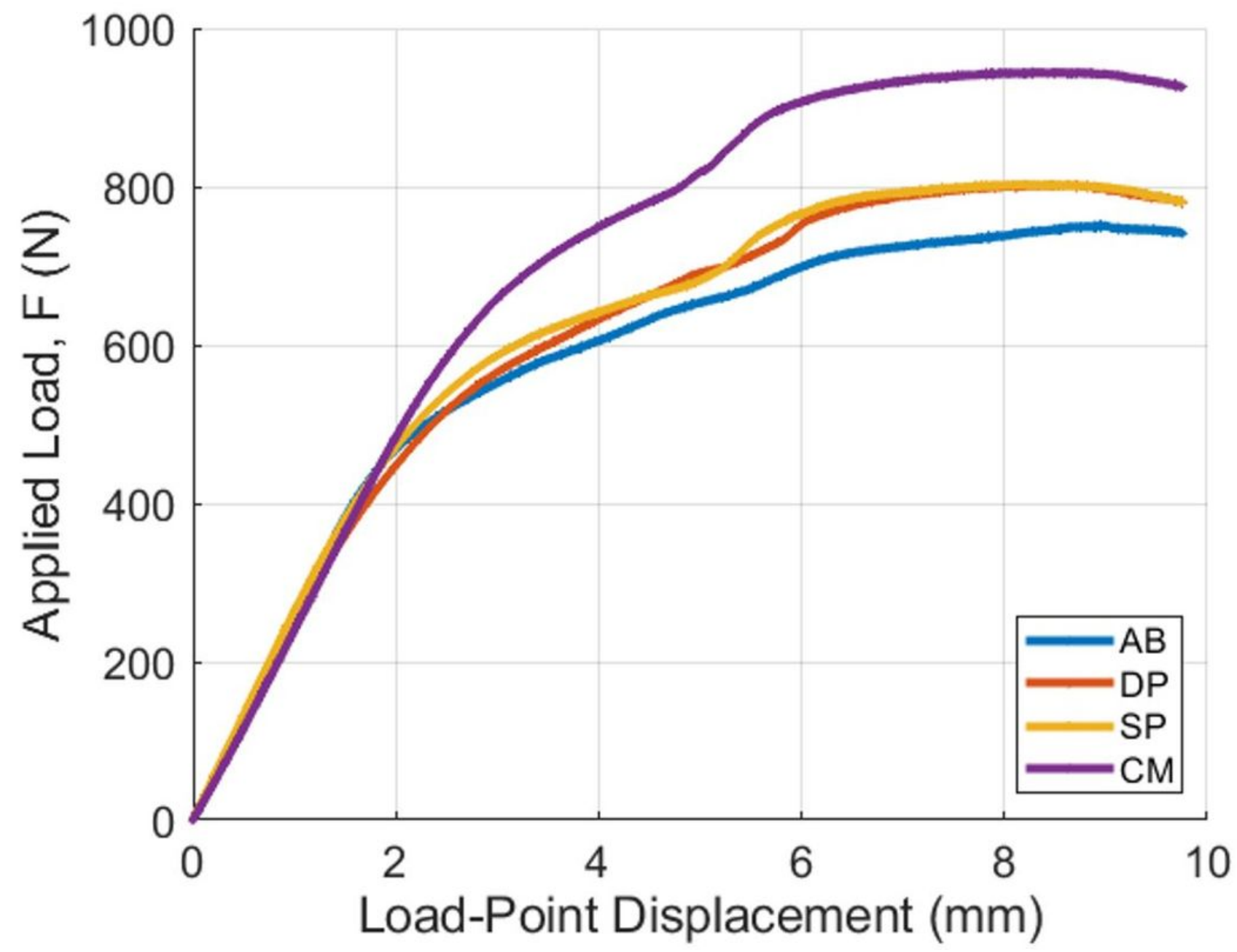

Figure 4

Quasi-static bending load-displacement curves of AB, DP, SP, and CM CPTi LC-DCPs 


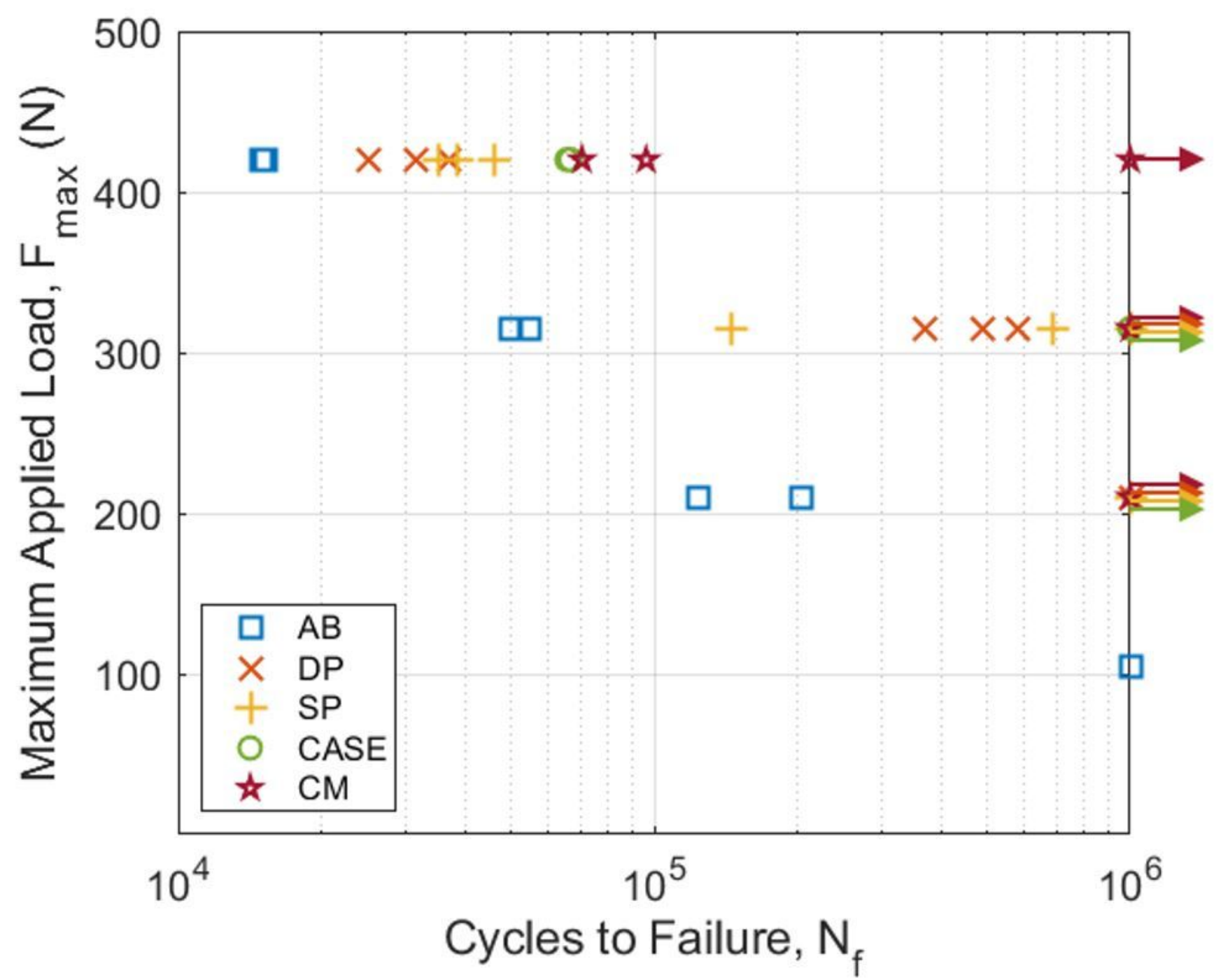

Figure 5

Bending fatigue plot of maximum applied load (Fmax) versus cycles to failure (Nf) for plates in five different manufacturing/surface conditions including AB, DP, SP, CASE, and CM 

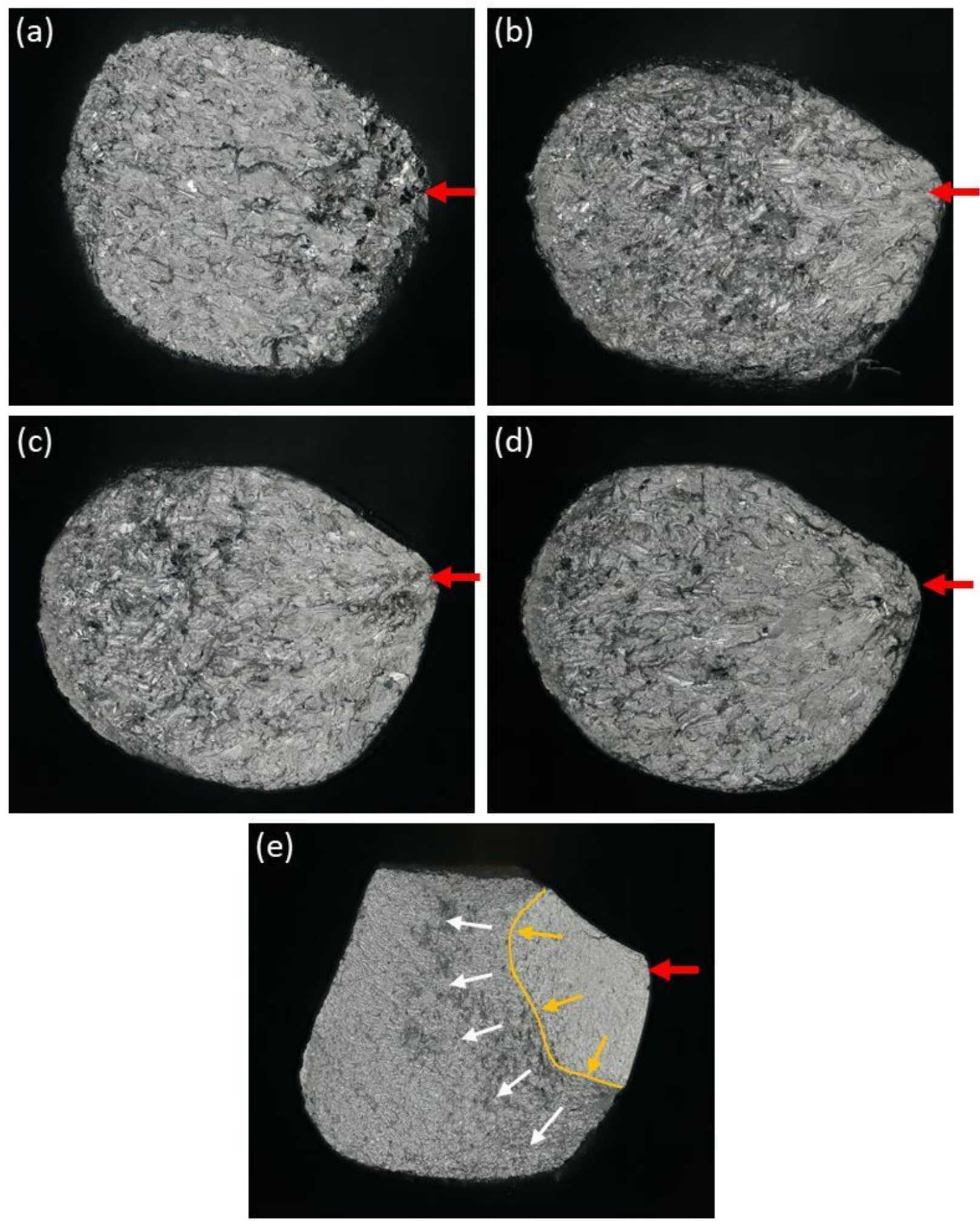

Figure 6

Fractography images of (a) AB, (b) DP, (c) SP, (d) CASE, and (e) CM CPTi LC-DCPs captured by the 3D digital microscope 

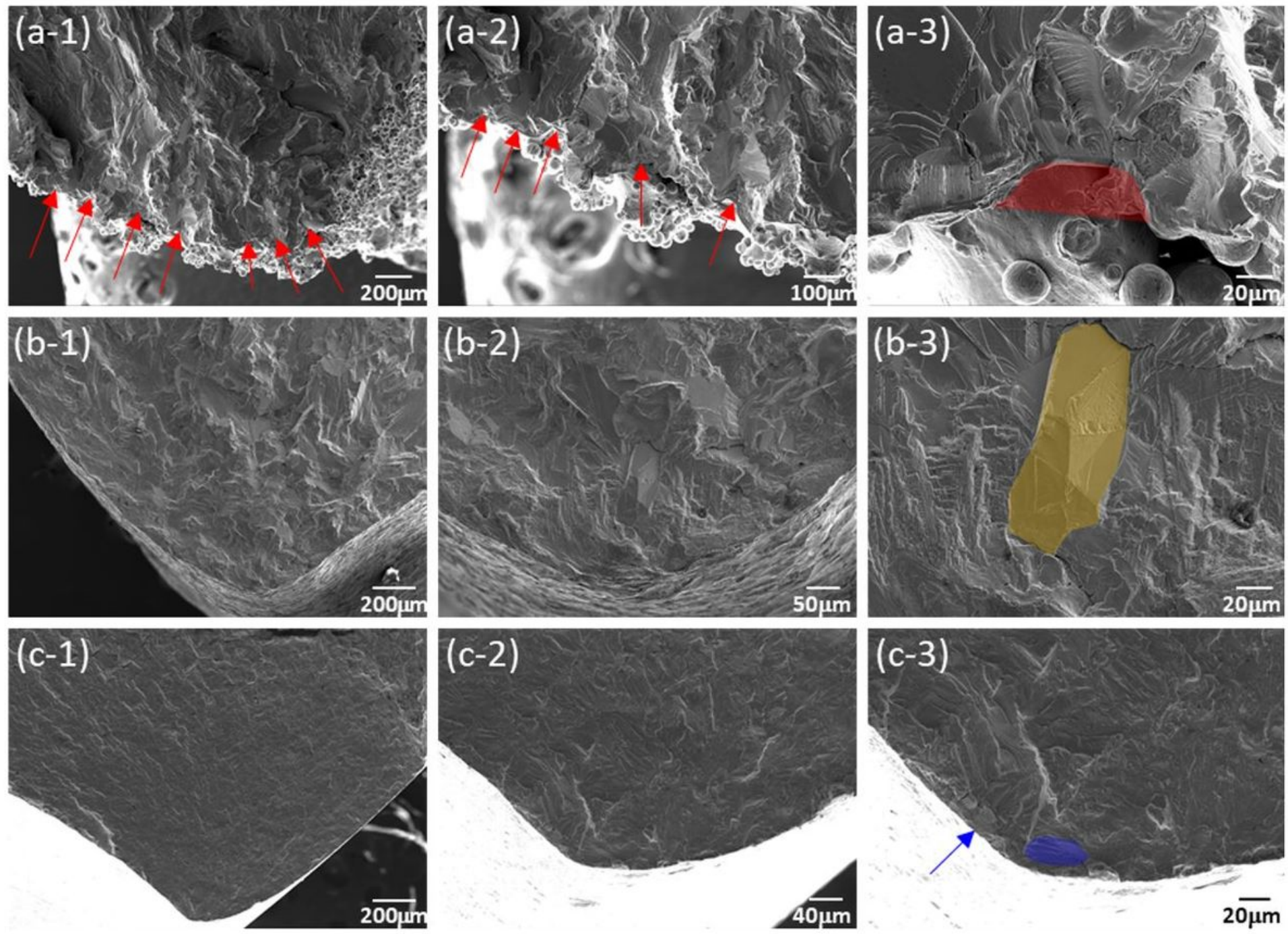

Figure 7

Fractography images of (a) AB, (b) DP, and (c) CM CPTi LC-DCPs captured by the scanning electron microscopy

\section{Supplementary Files}

This is a list of supplementary files associated with this preprint. Click to download.

- EffectofsurfacetreatmentCoverLeter.pdf 